cornea presented in front of the centre of the pupil a vertically placed chocolate coloured patch $3.5 \mathrm{~mm}$. long and $1 \mathrm{~mm}$. broad at the broadest central part. The fine pigment in the lozenge-shaped patch seemed to be distributed on Descemet's membrane, the actual depth and appearance of which will be noted by me on arrival of my slit-lamp. The fundi were normal except that the right fundus revealed a right angled bright white fibrous scar starting from a point half a disc diameter away from the nasal margin of the disc. The two limbs of the right angle ran tangentially to the disc, the upper one running upwards and outwards and the lower downwards and outwards. The free ends of the fibrous white scar got lost in a fan-shaped radiating manner in the slate-coloured retina.

This suggests the whole condition is a congenital anomaly. The peculiarity of my case is that the left eye is not myopic at all, and and the right eye only about a dioptre myopic and that in one meridian alone.

\title{
ANNOTATION
}

\section{Avertin in Ophthalmology}

The paper by Gayer Morgan and J. M. Lees in this issue calls attention to a comparatively new anaesthetic for use in ophthalmic cases. So far as we know, Wessely, in the Arch. f. Augenheilk., July, 1929, was the first ophthalmic surgeon to publish a record of cases anaesthetised with this drug. We believe that it has been given an extensive trial in general surgery and we understand that, with attention to the details specified hereunder, it is a perfectly safe anaesthetic.

The precautions to be observed comprise those connected with the drug and those connected with the patient. As to the first of these, 'the solution must be freshly prepared; it must not be heated above $38^{\circ} \mathrm{C}$., and it must be tested for the presence of free acid by a solution of congo red, 1 in 1,000.

With regard to the patient, rectal troubles, such as fistula, fissure, etc., contra-indicate its use. There must be no evidence of impaired renal function; no disturbance of hepatic or pancreatic function and no marked fall in the basal metabolic rate.

The dose should never exceed 0.1 gramme per kilo. of body weight, and with regard to the aged and in feeble subjects, even this is a high dosage.

On general principles it is undesirable to try and obtain full anaesthesia with avertin alone. The drug is to be considered rather as a deep narcotic than an essential anaesthetic. 